\title{
Association Between Parental Marital Status and Types of Suicidal Behavior Among Korean Adolescents: A Cross-sectional Study
}

\author{
Yoon Sik Park, Eun-Cheol Park \\ Department of Preventive Medicine and Institute of Health Services Research, Yonsei University College of Medicine, Seoul, Korea
}

Objectives: Adolescent suicide is a global problem. This study aimed to identify associations between parental marital status and suicidal behavior.

Methods: This study analyzed 118715 middle and high school students from the 13th and 14th Korea Youth Risk Behavior Web-based Survey. The odds ratios (ORs) of suicidal ideation, planning, and attempts were calculated based on parental marital status, living situation, and socioeconomic factors. The data were analyzed using multiple logistic regression.

Results: When compared to those living with 2 married biological parents, the ORs of suicidal ideation among adolescents living with either remarried or no parents were 1.34 (95\% confidence interval $[\mathrm{Cl}], 1.17$ to 1.53$)$ and 1.36 (95\% $\mathrm{Cl}, 1.11$ to 1.66$)$, respectively. For suicidal planning, the OR of those living with 1 remarried biological parent was 1.24 (95\% Cl, 1.01 to 1.52$)$, and that of those living without parents was $1.28(95 \% \mathrm{Cl}, 0.95$ to 1.73), when compared to adolescents living with 2 married biological parents. For suicide attempts, when compared to adolescents with 2 married biological parents, the OR of those living with 1 remarried biological parent was $1.48(95 \% \mathrm{Cl}, 1.17$ to 1.87$)$ and that of those living without parents was $2.02(95 \% \mathrm{Cl}, 1.44$ to 2.83$)$. For adolescents living with 1 remarried biological parent, suicidal behavior was strongly associated with having no siblings and were weakly associated with not living with grandparents.

Conclusions: Suicidal behavior among adolescents was associated with the remarriage and loss of parents. Therefore, special attention and interventions are needed for adolescents in those situations.

Key words: Parental marital status, Family, Suicidal behavior, Adolescents, Mental health, Korea Youth Risk Behavior Web-based Survey

\section{INTRODUCTION}

Korea has the second highest suicide rate among the coun-

Received: January 4, 2020 Accepted: August 11, 2020

Corresponding author: Eun-Cheol Park, MD, PhD Department of Preventive Medicine and Institute of Health Services Research, Yonsei University College of Medicine, 50-1 Yonsei-ro, Seodaemun-gu, Seoul 03722, Korea

E-mail: ecpark@yuhs.ac

This is an Open Access article distributed under the terms of the Creative Commons Attribution Non-Commercial License (https://creativecommons.org/licenses/bync/4.0/) which permits unrestricted non-commercial use, distribution, and reproduction in any medium, provided the original work is properly cited. tries in the Organization for Economic Cooperation and Development as of 2016, and it has moved closer to first place [1]. In adolescents, the suicide rate was 7.3 per 100000 people in 2006, which increased to 10.8 in 2018 [2]. In 2006, suicide was the second leading cause of mortality among Korean adolescents, following transportation accidents, but as of 2018 it became the top cause of death, underscoring its importance as a major social issue [2].

Adolescents' mental health is strongly affected by their fam- 
ily, and especially their parents. Adolescents who receive less emotional support from their families are more likely to experience social adversities, such as academic problems, conflicts in peer relationships, and self-hating behaviors $[3,4]$. Further research has shown that family dysfunction influences emotional depression among adolescents, which contributes to behaviors such as suicide [5]. Prior studies have suggested that adolescents in single or stepparent families are more likely to be depressed and show higher rates of suicidal behavior than are those at the same age living with 2 biological parents $[6,7]$. Socioeconomic status (SES) and family structure also affect suicidal behavior among adolescents [8,9]. An adverse family structure could negatively influence children's academic achievements [10]. Another study found that adolescents with either a single mother or no parents had lower academic performance levels than their counterparts [11]. The mental health of adolescents is therefore negatively affected by changes in various family factors. In Korea, divorce has become more common in the last 10 years [12]. Therefore, the crisis of family dysfunction with broken marriages could pose an increasingly serious problem in the future.

Therefore, it is important to identify the risk factors for suicide in adolescents associated with their family structure. Previous studies have shown that family structure influenced suicidal behavior, but most of those studies had a small sample size [5], analyzed non-Korean populations [13], or did not consider all types of suicidal behavior [14]. To address these limitations, this study utilized a large sample size and included a full range of suicidal behavior (ideation, planning, and attempts).

We categorized parental marital status into several groups and analyzed their correlations with suicidal behavior. Moreover, to increase the level of detail and precision of the analysis, other familial factors relevant to adolescents (e.g., the presence of siblings or grandparents, co-residence status with family, and multicultural family composition) were included. Therefore, the primary objective of this study was to augment the findings of previous studies and to describe, in detail, the association between parental marital status and suicidal ideation, planning, and attempts among Korean adolescents.

\section{METHODS}

\section{Study Sample}

The study data were collected between 2017 and 2018 from the Korea Youth Risk Behavior Web-based Survey (KYRBWS), which is conducted by the Korea Centers for Disease Control and Prevention among middle and high school students. The KYRBWS is a cross-sectional, nationally representative survey that has been conducted annually since 2005 to examine the general health behaviors of Korean adolescents. The survey consists of 123 questions assessing adolescents' demographic characteristics, as well as 14 categories of health behaviors, including tobacco smoking, alcohol drinking, obesity and weight control, physical activity, eating habits, injury prevention, sexual behaviors, mental health, Internet addiction, dental health, allergic diseases, personal hygiene, health equity, and substance abuse. The test-retest reliability of the KYRBWS questionnaire has been reported to be stable [15].

The initial sample included 122316 individuals of middle and high school age, under 19 years old, who were interviewed and surveyed for the KYRBWS in 2017 and 2018. This study excluded participants who either gave incomplete answers or had missing values. The total number of eligible participants in the final sample was 118715 .

\section{Suicidal Behavior}

Three questions were used to define types of suicidal behavior. First, answering "yes" to the question "In the last 12 months, have you seriously considered suicide?" was defined as suicidal ideation. Second, a response of "yes" to the question "In the last 12 months, have you made specific plans for suicide?" indicated suicidal planning. Last, answering "yes" to the question "In the last 12 months, have you attempted suicide?" demonstrated the occurrence of suicide attempts.

\section{Parent Marital Status}

Family factors were assessed using questions about the presence of parents and their marital status (father, mother, stepfather, or stepmother). Adolescents who lived with both their biological father and mother were defined as having "both biological parents." Those who lived with either their biological father or their biological mother were included in the "single biological parent" group. Those living with 1 biological parent and 1 stepparent were placed in the "second marriage" group. Adolescents who lived with both a stepfather and stepmother or only a single stepparent were included in the "adoptive parent" group. Finally, those who met none of the aforementioned category criteria were categorized as "none." 


\section{Covariates}

The presence of siblings and grandparents, living in a multicultural family, and living with one's family were included as familial factors. Sex, age, household income, current region of residence, current educational grade, and academic achievements were included as socioeconomic factors. Obesity, eating habits, lifetime smoking status, frequency of alcohol consumption, feeling stressed, and engaging in physical activity were included as health-related factors. Obesity was measured using participants' body mass index as normal $\left(<25 \mathrm{~kg} / \mathrm{m}^{2}\right)$ or obese $\left(\geq 25 \mathrm{~kg} / \mathrm{m}^{2}\right)$.

\section{Statistical Analysis}

The chi-square test were used to evaluate the basic characteristics of the participants. Multiple logistic regression models were created to determine whether parental marital status was related to suicidal behavior among adolescents. In model 1 , the variable of interest was parental marital status, with the dependent variables being suicidal ideation, planning, and attempts, as well as participants' adjusted SES, familial factors, and health-related factors. Additionally, an independent subgroup analysis was performed according to whether participants lived with their families, whether they had a multicultural family, and the presence of siblings and grandparents through multiple logistic regression. All statistical analyses were performed using SAS version 9.4 (SAS Institute Inc., Cary, NC, USA).

\section{Ethics Statement}

This study used already existing data established by government, therefore institutional review board approval was not needed.

\section{RESULTS}

The participants' general characteristics according to each suicidal behavior are shown in Table 1. A total of 118175 participants were included in the study, of whom 108306 (91.2\%) lived with both biological parents, 5631 (4.7\%) with a single biological parent, 2091 (1.8\%) with parents in a second marriage, $1778(1.5 \%)$ with adoptive parents, and $909(0.8 \%)$ with no parents. In terms of suicidal behavior, 14708 (12.4\%) participants had considered suicide, 4675 (3.9\%) had planned it, and $3142(2.6 \%)$ had attempted suicide. In Korea, the suicide attempt rate among adolescents is about 3\% [2], and the re- sults of this survey can therefore be considered reliable.

The first regression model showed the estimated odds ratios (ORs) of suicidal behavior from the multiple logistic regression analysis (Table 2). Compared to those with both biological parents, the ORs were higher for those living with parents in a second marriage and those living with no parents (suicidal ideation: 1.34 [95\% confidence interval; $\mathrm{Cl}, 1.17$ to 1.53 ] and 1.36 [95\% Cl, 1.11 to 1.66], respectively; suicidal planning: 1.24 [95\% Cl, 1.01 to 1.52] and 1.28 [95\% Cl, 0.95 to 1.73], respectively; suicide attempts: 1.48 [95\% Cl, 1.17 to 1.87$]$ and 2.02 [95\% Cl, 1.44 to 2.83], respectively). The other groups, such as those living with a single biological parent or adoptive parents showed no meaningful ORs for any of the types of suicidal behavior. Other covariates were associated with suicidal behavior, such as female sex, younger age, lower academic achievements, heavy alcohol use, lifetime smoking experience, experiencing stress, and low physical activity levels (Table 2).

The second multiple logistic regression model analyzed the associations between several familial factors and suicidal behavior (Table 3). For the 3 types of suicidal behavior, the presence of a sibling was the most significant familial factor. For suicidal ideation, when compared to adolescents with both biological parents, if there were no siblings present, the ORs were $1.17(95 \% \mathrm{Cl}, 1.00$ to 1.37$)$ in the single biological parent group, $1.78(95 \% \mathrm{Cl}, 1.33$ to 2.29$)$ in the second marriage group, and $1.36(95 \% \mathrm{Cl}, 1.05$ to 1.76$)$ in the no parents group. The ORs for suicidal planning were $1.32(95 \% \mathrm{Cl}, 1.03$ to 1.69$), 1.78$ ( $95 \% \mathrm{Cl}, 1.20$ to 2.64 ), and 1.68 ( $95 \% \mathrm{Cl}, 1.17$ to 2.43 ) for these groups, respectively. For suicide attempts, the ORs were 1.25 ( $95 \% \mathrm{Cl}, 0.93$ to 1.67 ), 1.82 (95\% Cl, 1.13 to 2.95 ), and 2.12 $(95 \% \mathrm{Cl}, 1.40$ to 3.21$)$, respectively. In the adoptive parents group, there were no ORs of statistical significance. The presence of grandparents showed a meaningful effect in the group with no parents, with ORs of 1.42 ( $95 \% \mathrm{Cl}, 1.10$ to 1.83$), 1.47$ (95\% $\mathrm{Cl}, 1.00$ to 2.15$)$, and 2.37 ( $95 \% \mathrm{Cl}, 1.55$ to 3.61 ) for suicidal ideation, planning, and attempts, respectively, for adolescents without grandparents in this group when compared to adolescents living with both biological parents.

\section{DISCUSSION}

This cross-sectional study examined the association of parental marital status with suicidal behavior in the Korean adolescent population. Statistically significant differences were found in the prevalence of suicidal behavior among adolescents 


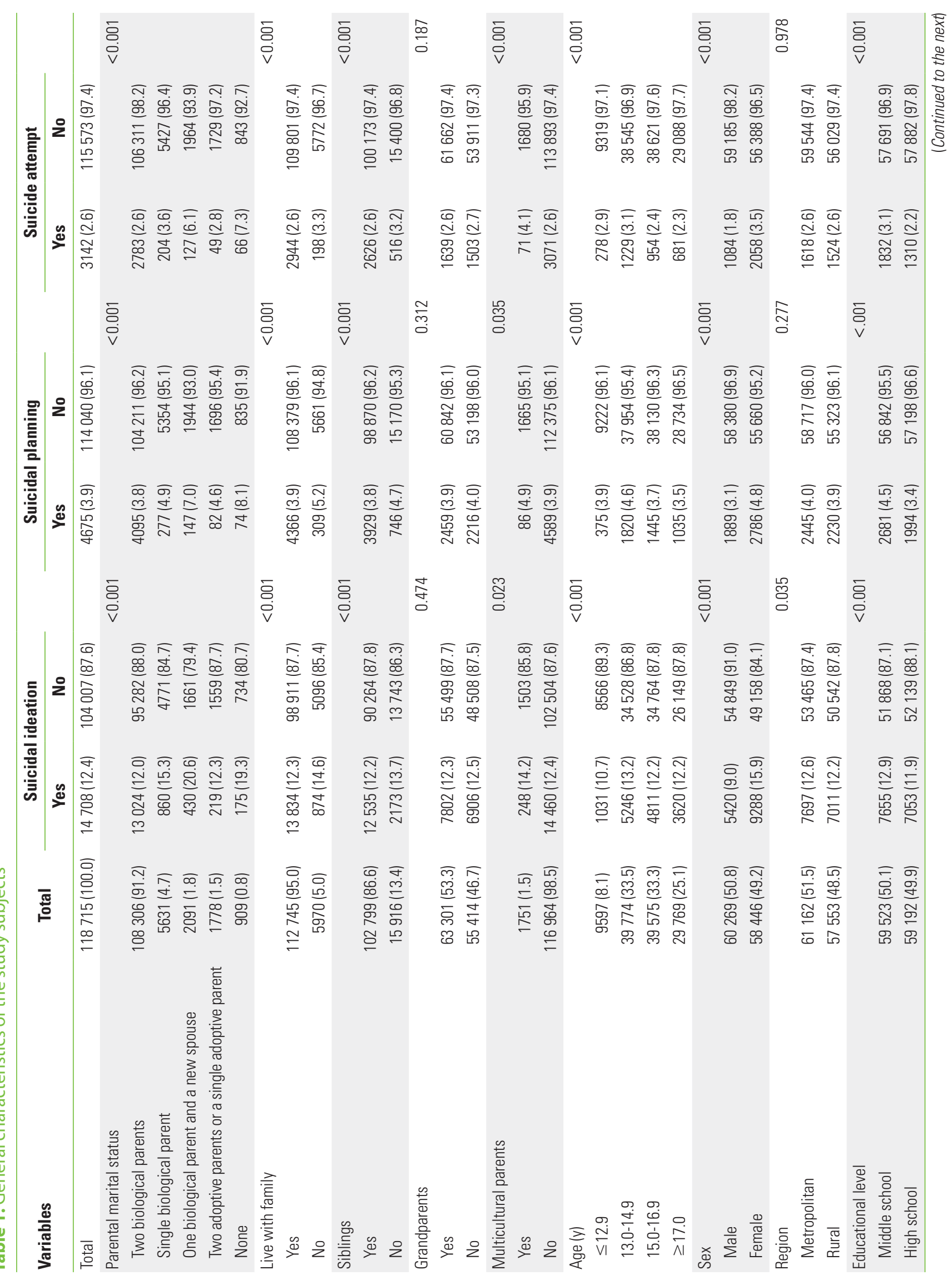




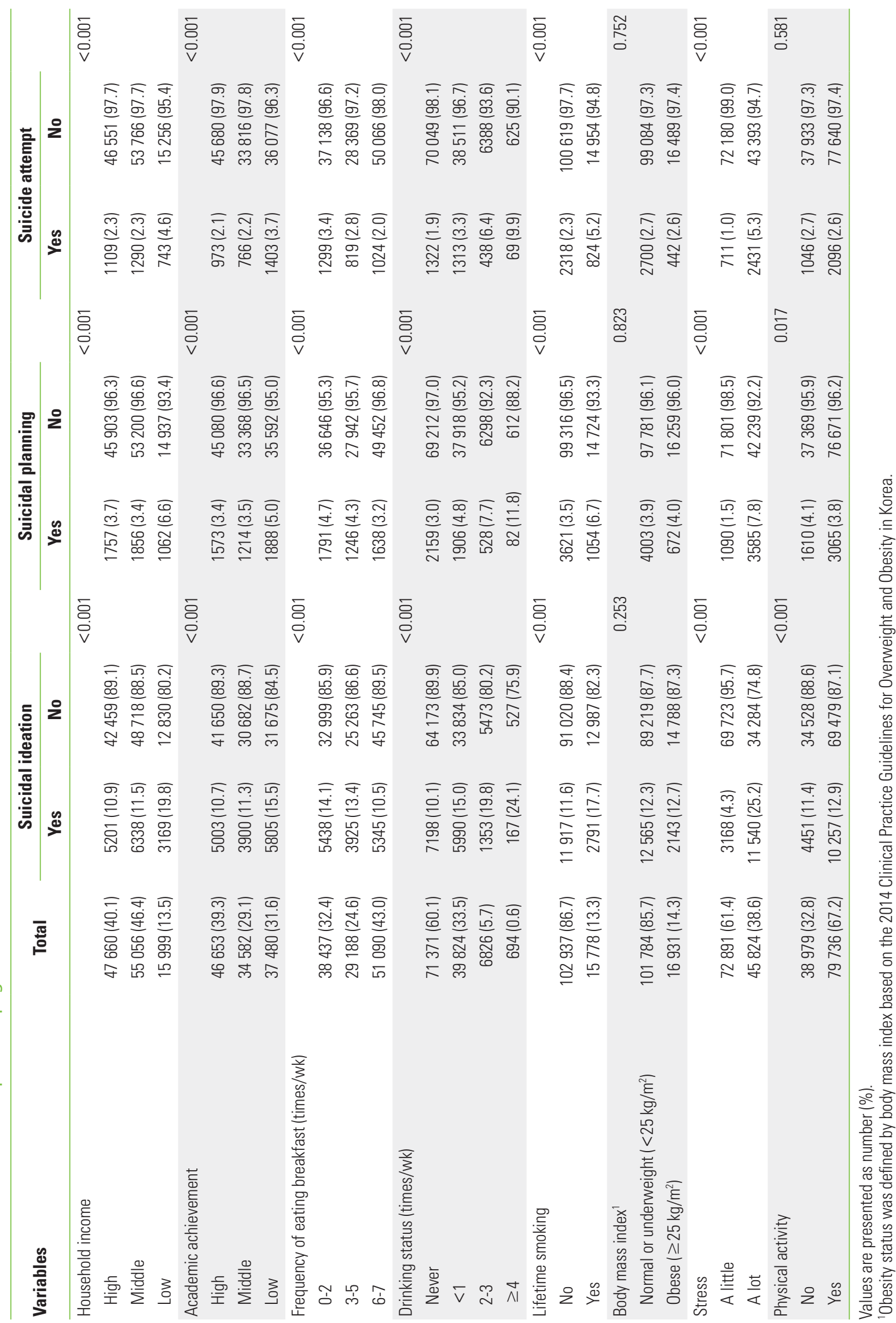


Table 2. Association between parental parital status and suicidal behaviors

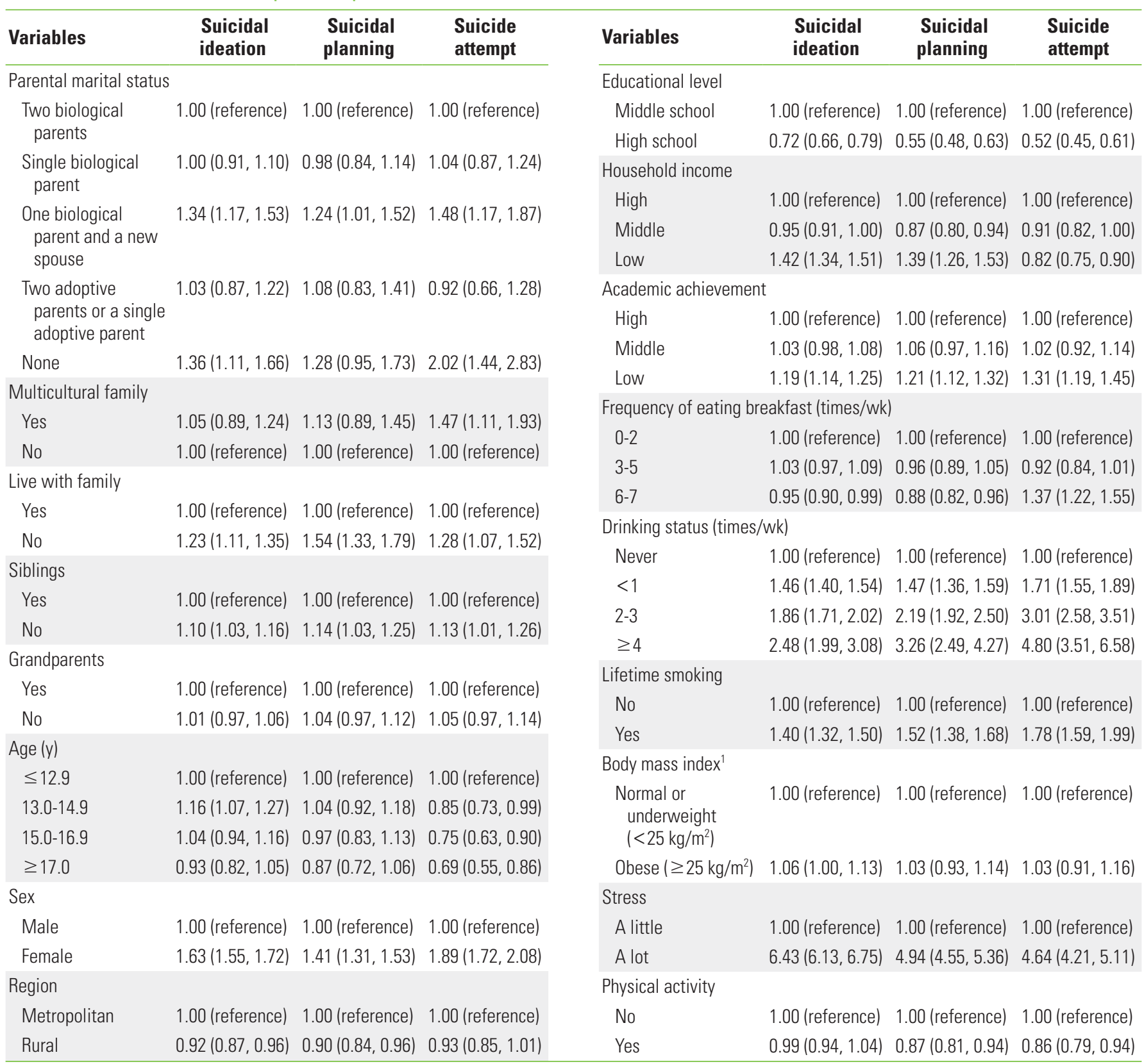

Values are presented as odds ratio ( $95 \%$ confidence interval).

${ }^{1}$ Obesity status was defined by body mass index based on the 2014 Clinical Practice Guidelines for Overweight and Obesity in Korea.

according to their living situation in terms of marital status. Compared to adolescents living with both biological parents, those in the second marriage were more likely to have suicidal behavior, with ORs of $1.34(95 \% \mathrm{Cl}, 1.17$ to 1.53$), 1.24(95 \% \mathrm{Cl}$, 1.01 to 1.52$)$, and $1.48(95 \% \mathrm{Cl}, 1.17$ to 1.87$)$ for suicidal ideation, planning, and attempts, respectively. These findings are consistent with those of a previous study that found that remarriage had negative associations with suicidal behavior in both children and adolescents [16]. In the parent-child relationship, the impact of a parent's remarriage on their children is larger than that of either going through a divorce or dying $[14,17]$. This result could indicate that the presence of a new stepparent causes a sense of detachment with the biological parent, with these changes consequently affecting the quality of life and mental health of adolescents and younger children [14].

Another finding of this study is that the single biological 
Table 3. Independent subgroup analysis of suicidal behaviors

\begin{tabular}{|c|c|c|c|c|c|}
\hline Variables & $\begin{array}{l}\text { Two biological } \\
\text { parents }\end{array}$ & $\begin{array}{l}\text { Single biological } \\
\text { parent }\end{array}$ & $\begin{array}{l}\text { One biological parent } \\
\text { and a new spouse }\end{array}$ & $\begin{array}{l}\text { Two adoptive parents or a } \\
\text { single adoptive parent }\end{array}$ & None \\
\hline \multicolumn{6}{|c|}{ Suicidal ideation } \\
\hline \multicolumn{6}{|c|}{ Live with family } \\
\hline Yes & 1.00 (reference) & $1.00(0.91,1.10)$ & $1.35(1.18,1.55)$ & $1.02(0.86,1.22)$ & $1.32(1.02,1.71)$ \\
\hline No & 1.00 (reference) & $0.99(0.72,1.36)$ & $1.23(0.80,1.88)$ & $1.07(0.57,2.01)$ & $1.15(0.79,1.67)$ \\
\hline \multicolumn{6}{|c|}{ Multicultural parents } \\
\hline Yes & 1.00 (reference) & $0.97(0.49,1.93)$ & $0.59(0.25,1.38)$ & $1.68(0.75,3.74)$ & $1.11(0.74,1.64)$ \\
\hline No & 1.00 (reference) & $1.00(0.91,1.10)$ & $1.38(1.20,1.57)$ & $1.00(0.84,1.19)$ & $1.36(1.12,1.66)$ \\
\hline \multicolumn{6}{|c|}{ Existence of siblings } \\
\hline Yes & 1.00 (reference) & $0.94(0.84,1.05)$ & $1.25(1.07,1.45)$ & $0.99(0.82,1.19)$ & $1.22(0.82,1.82)$ \\
\hline No & 1.00 (reference) & $1.17(1.00,1.37)$ & $1.78(1.33,2.39)$ & $1.31(0.81,2.14)$ & $1.36(1.05,1.76)$ \\
\hline \multicolumn{6}{|c|}{ Existence of grandparents } \\
\hline Yes & 1.00 (reference) & $1.04(0.91,1.18)$ & $1.29(1.08,1.54)$ & $1.09(0.90,1.31)$ & $1.20(0.87,1.66)$ \\
\hline No & 1.00 (reference) & $0.97(0.85,1.10)$ & $1.39(1.15,1.70)$ & $0.85(0.57,1.27)$ & $1.42(1.10,1.83)$ \\
\hline \multicolumn{6}{|c|}{ Suicidal planning } \\
\hline \multicolumn{6}{|c|}{ Live with family } \\
\hline Yes & 1.00 (reference) & $1.00(0.85,1.17)$ & $1.29(1.04,1.60)$ & $1.02(0.76,1.36)$ & $1.33(0.90,1.96)$ \\
\hline No & 1.00 (reference) & $0.83(0.51,1.36)$ & $0.99(0.53,1.87)$ & $1.08(0.45,2.59)$ & $0.87(0.54,1.41)$ \\
\hline \multicolumn{6}{|c|}{ Multicultural parents } \\
\hline Yes & 1.00 (reference) & $0.98(0.42,2.32)$ & $0.13(0.02,0.69)$ & $1.04(0.27,4.02)$ & $0.52(0.28,0.97)$ \\
\hline No & 1.00 (reference) & $0.98(0.84,1.14)$ & $1.31(1.07,1.61)$ & $1.04(0.79,1.38)$ & $1.31(0.97,1.77)$ \\
\hline \multicolumn{6}{|c|}{ Existence of siblings } \\
\hline Yes & 1.00 (reference) & $0.86(0.71,1.04)$ & $1.12(0.89,1.42)$ & $1.08(0.81,1.44)$ & $0.50(0.23,1.08)$ \\
\hline No & 1.00 (reference) & $1.32(1.03,1.69)$ & $1.78(1.20,2.64)$ & $1.02(0.49,2.15)$ & $1.68(1.17,2.43)$ \\
\hline \multicolumn{6}{|c|}{ Existence of grandparents } \\
\hline Yes & 1.00 (reference) & $0.98(0.79,1.22)$ & $1.27(0.97,1.66)$ & $1.19(0.89,1.58)$ & $0.72(0.42,1.25)$ \\
\hline No & 1.00 (reference) & $0.98(0.80,1.21)$ & $1.22(0.89,1.66)$ & $0.72(0.37,1.38)$ & $1.47(1.00,2.15)$ \\
\hline \multicolumn{6}{|c|}{ Suicide attempt } \\
\hline \multicolumn{6}{|c|}{ Live with family } \\
\hline Yes & 1.00 (reference) & $1.03(0.86,1.25)$ & $1.42(1.11,1.81)$ & $0.87(0.61,1.24)$ & $1.91(1.25,2.94)$ \\
\hline No & 1.00 (reference) & $1.18(0.69,2.00)$ & $2.32(1.19,4.50)$ & $0.76(0.23,2.58)$ & $1.73(0.93,3.21)$ \\
\hline \multicolumn{6}{|c|}{ Multicultural parents } \\
\hline Yes & 1.00 (reference) & $0.86(0.30,2.49)$ & $0.68(0.19,2.45)$ & $0.35(0.10,1.29)$ & $0.43(0.20,0.94)$ \\
\hline No & 1.00 (reference) & $1.04(0.87,1.24)$ & $1.53(1.20,1.94)$ & $0.91(0.65,1.28)$ & $2.08(1.48,2.91)$ \\
\hline \multicolumn{6}{|c|}{ Existence of siblings } \\
\hline Yes & 1.00 (reference) & $0.96(0.77,1.21)$ & $1.40(1.07,1.84)$ & $0.92(0.65,1.29)$ & $1.31(0.64,2.69)$ \\
\hline No & 1.00 (reference) & $1.25(0.93,1.67)$ & $1.82(1.13,2.95)$ & $0.83(0.31,2.23)$ & $2.12(1.40,3.21)$ \\
\hline \multicolumn{6}{|c|}{ Existence of grandparents } \\
\hline Yes & 1.00 (reference) & $0.96(0.74,1.24)$ & $1.71(1.30,2.26)$ & $1.15(0.81,1.63)$ & $1.23(0.70,2.15)$ \\
\hline No & 1.00 (reference) & $1.10(0.87,1.39)$ & $1.20(0.83,1.74)$ & $0.35(0.14,0.89)$ & $2.37(1.55,3.61)$ \\
\hline
\end{tabular}

Values are presented as odds ratio ( $95 \%$ confidence interval).

parent group showed no statistically significant differences from the reference group. However, a previous study on suicide in adolescents suggested that parental separation or divorce had negative associations with their child's mental health [18].
Moreover, people who experience these types of situations during childhood show a heightened prevalence of suicidal behavior during adulthood $[19,20]$. In this study, the impact of divorce or separation of one's parents may have been under- 
estimated relative to what occurs in reality, due to the crosssectional design.

After analyzing the variables of interest by independent subgroups, some significant findings were identified. The absence of a sibling impacted the suicidal behavior of adolescents in most groups, except for the adoptive parents group. This result implies that having siblings_-regardless of age or sex-could be a prominent emotionally supportive factor for children and adolescents. This finding is somewhat consistent with the result of a previous study reporting that a sense of social detachment increased suicidal thoughts among girls [21]. In practice, according to this evidence, adolescents in certain situations (e.g., those living with remarried parents or no parents), should be socially and emotionally supported-particularly those without siblings.

The association between suicidal behavior and the presence of grandparents was trivial in most groups, except for adolescents living without parents. Although no statistical significance was found, adolescents seemed to be more vulnerable in each category of suicidal behavior when they lived without any grandparents. This result implies that, if an adolescent has no parents, they subsequently become reliant on their grandparents. Although the emotional connection between grandparents and grandchildren is weaker than the parent-child relationship, it could play some role in emotional support [22]. In this scenario, the life expectancy of the primary caregiver of the child is relatively short and the household income may be low. Therefore, both economic and healthcare support should be provided to this kind of family unit until the child reaches adulthood.

This study has some limitations. First, the study utilized a cross-sectional design; therefore, causality cannot be established. The associations found by this study should therefore be confirmed by longitudinal or other research designs. Second, our research might have validity issues, as we used selfreported measures of suicidal behavior. Moreover, social desirability bias may exist due to the potential reluctance of participants to respond honestly regarding their suicidal behavior. Third, this study did not show or examine any gender differences as participants' gender was simply included as an independent variable. Fourth, before conducting this study, we expected to see racial differences in participants' responses, but this did not turn out to be the case [23]. A larger and more precise study is therefore needed in order to compare multicultural groups. Finally, in this survey, there were no questions about the relationship between parents and their children. Therefore, the quality of the relationships between the parents and children was not measured.

Despite these limitations, this study has strengths, especially its large sample size and comprehensive treatment of types of suicidal behavior, especially when compared to previous research. Numerous studies have been conducted on associations between family structure and the mental health of adolescents. This study, however, is the first to consider all aspects of suicidal behavior, including ideation, planning, and attempts, in the Korean adolescent population. In addition, the analysis not only considered parental factors, but also took into account familial factors (e.g., the presence of siblings and grandparents) that may affect the suicidal behavior of adolescents. Unfortunately, in Korea, there is insufficient governmental support targeting remarried or reconstructed families. There are welfare policies aimed at people who are disabled, multicultural families, low-income families, and single-parent families, but none specifically targeting remarried or reconstructed families [24]. It is also difficult to find policies about reconstructed families in foreign countries. Although some studies have documented the financial advantages of remarriage $[25,26]$, mental health management in reconstructed families was out of the scope of those studies. Herein, we found evidence for mental health vulnerabilities in reconstructed or remarried families, implying that the government needs to pay more attention to adolescents living in these situation.

In conclusion, we found that parental marital status was associated with suicidal behavior among adolescents. Compared to adolescents who have both biological parents present, those with remarried parents were at a higher risk. Families with no parents were the most vulnerable family structure for adolescents in terms of their mental health. Adoptive family structures showed a lower risk for suicidal behavior, although these trends were not statistically significant. This implies that the proper adoption of orphans might be beneficial to their mental health. However, this scenario should be approached carefully so that other problems are not inadvertently caused. Therefore, adolescents in these situations should be supported by either their school or other relevant institutions. Although this association has yet to be confirmed by longitudinal or causal studies, our results support the notion that family structure is an important part of the mental health status of adolescents and should therefore be considered in societal healthcare policies. 


\section{CONFLICT OF INTEREST}

The authors have no conflicts of interest associated with the material presented in this paper.

\section{FUNDING}

None.

\section{ACKNOWLEDGEMENTS}

This study used data from the 14th Korea Youth Risk Behavior Web-based Survey, 2018, Ministry of Education, Ministry of Health and Welfare, Centers for Disease Control and Prevention.

\section{AUTHOR CONTRIBUTIONS}

Conceptualization: YSP. Data curation: YSP. Formal analysis: YSP. Funding acquisition: None. Methodology: YSP. Project administration: YSP. Writing - original draft: YSP. Writing - review \& editing: $E C P$.

\section{ORCID}

Yoon Sik Park https://orcid.org/0000-0002-8269-0169

Eun-Cheol Park https://orcid.org/0000-0002-2306-5398

\section{REFERENCES}

1. Organisation for Economic Co-operation and Development (OECD). OECD statistics: intentional self-harm (indicator) [cited 2019 Oct 30]. Available from: https://stats.oecd.org/index. aspx?queryid $=30115$.

2. Korean Statistical Information Service. Statistical database: health - cause of death (indicator) [cited 2019 Oct 30]. Available from: http://kosis.kr/eng/statisticsList/statisticsListIndex. do? menuld = M_01_01\&vwcd = MT_ETITLE\&parmTabld $=$ M_ 01_01.

3. Barber BK, Erickson LD. Adolescent social initiative: antecedents in the ecology of social connections. J Adolesc Res 2001; 16(4):326-354.

4. Roizblatt SA, Leiva FV, Maida SA. Parents separation or divorce. Potential effects on children and recommendations to parents and pediatricians. Rev Chil Pediatr 2018;89(2):166-172 (Span- ish).

5. Martin G, Rozanes P, Pearce C, Allison S. Adolescent suicide, depression and family dysfunction. Acta Psychiatr Scand 1995; 92(5):336-344.

6. Garnefski N, Diekstra RF. Adolescents from one parent, stepparent and intact families: emotional problems and suicide attempts. J Adolesc 1997;20(2):201-208.

7. Perales F, Johnson SE, Baxter J, Lawrence D, Zubrick SR. Family structure and childhood mental disorders: new findings from Australia. Soc Psychiatry Psychiatr Epidemiol 2017;52(4):423433.

8. Santelli JS, Lowry R, Brener ND, Robin L. The association of sexual behaviors with socioeconomic status, family structure, and race/ethnicity among US adolescents. Am J Public Health 2000;90(10):1582-1588.

9. Lee DW, Shin J, Choi DW, Kim K, Park EC. Effects of household income change on children's problem behavior: findings from a longitudinal study. J Adolesc Health 2019;65(4):527-535.

10. Lee D, McLanahan S. Family structure transitions and child development: instability, selection, and population heterogeneity. Am Sociol Rev 2015;80(4):738-763.

11. Heard HE. The family structure trajectory and adolescent school performance: differential effects by race and ethnicity. J Fam Issues 2007;28(3):319-354.

12. Korean Statistical Information Service. Statistical database: population-vital status (indicator) [cited 2020 Jun 30]. Available from: http://kosis.kr/eng/statisticsList/statisticsListIndex. do?menuld=M_01_01\&vwcd = MT_ETITLE\&parmTabld = M 01_01\&statld =1962001\&themald =\#A_3.2.

13. Ponnet K, Vermeiren R, Jespers I, Mussche B, Ruchkin V, SchwabStone $M$, et al. Suicidal behaviour in adolescents: associations with parental marital status and perceived parent-adolescent relationship. J Affect Disord 2005;89(1-3):107-113.

14. Lee K, Namkoong K, Choi WJ, Park JY. The relationship between parental marital status and suicidal ideation and attempts by gender in adolescents: results from a nationally representative Korean sample. Compr Psychiatry 2014;55(5):1093-1099.

15. Bae J, Joung H, Kim JY, Kwon KN, Kim YT, Park SW. Test-retest reliability of a questionnaire for the Korea Youth Risk Behavior Web-based Survey. J Prev Med Public Health 2010;43(5):403410.

16. Cherlin AJ, Furstenberg FF Jr. Stepfamilies in the United States: a reconsideration. Annu Rev Sociol 1994:20(1):359-381.

17. Rubenstein JL, Halton A, Kasten L, Rubin C, Stechler G. Suicidal behavior in adolescents: stress and protection in different 
family contexts. Am J Orthopsychiatry 1998;68(2):274-284.

18. Thompson RG Jr, Alonzo D, Hu MC, Hasin DS. The influences of parental divorce and maternal-versus-paternal alcohol abuse on offspring lifetime suicide attempt. Drug Alcohol Rev 2017; 36(3):408-414.

19. Lindström M, Rosvall M. Parental separation in childhood, social capital, and suicide thoughts and suicide attempts: a population-based study. Psychiatry Res 2015;229(1-2):206-213.

20. Hollingshaus MS, Smith KR. Life and death in the family: early parental death, parental remarriage, and offspring suicide risk in adulthood. Soc Sci Med 2015;131:181-189.

21. Bearman PS, Moody J. Suicide and friendships among American adolescents. Am J Public Health 2004;94(1):89-95.

22. Attar-Schwartz S. Emotional closeness to parents and grandparents: a moderated mediation model predicting adolescent adjustment. Am J Orthopsychiatry 2015;85(5):495-503.

23. Blum RW, Beuhring T, Shew ML, Bearinger LH, Sieving RE, Resnick MD. The effects of race/ethnicity, income, and family structure on adolescent risk behaviors. Am J Public Health 2000;90(12):1879-1884.

24. Ministry of Health and Welfare. Welfare services at a glance [cited 2019 Dec 20]. Available from: http://bokjiro.go.kr/nwel/ html/world/en/list.html.

25. Bahr SJ. The effects of welfare on marital stability and remarriage. J Marriage Fam 1979;41(3):553-560.

26. Dewilde C, Uunk W. Remarriage as a way to overcome the financial consequences of divorce-a test of the economic need hypothesis for European women. Eur Sociol Rev 2008;24(3): 393-407. 